\title{
STRUKTUR AFFINE ALJABAR LIE REAL DARI GRUP LIE SIMILITUDE BERDIMENSI 4
}

\author{
Edi Kurniadi', Nurul Gusriani², Betty Subartini ${ }^{3}$ \\ 1,2,3 Departemen Matematika FMIPA Unpad, Jl. Raya Bandung Sumedang KM.21, Bandung, Indonesia \\ Email: edi.kurniadi@unpad.ac.id
}

\begin{abstract}
In the present paper, we study some properties of a real Lie algebra of the similitude Lie group of dimension 4 which affine structures are contained. The purpose of this research is to prove that the real Lie algebra of the similitude Lie group of dimension 4 has affine structures. To obtain this, we compute the formula of affine structures with respect to its basis which is induced from symplectic structure. Moreover, the method used in this research is literature reviews to some related paper. As the main result, we obtain the explicit formulas of affine structures for its Lie algebra.
\end{abstract}

Keywords: Affine structures, lie algebras, similitude lie group.

\section{ABSTRAK}

Dalam artikel ini, dibahas tentang sifat-sifat aljabar Lie real dari grup Lie similitude berdimensi 4 termasuk struktur affine yang termuat di dalamnya. Tujuannya adalah untuk membuktikan bahwa aljabar Lie real dari grup Lie similitude berdimensi 4 mempunyai struktur affine. Untuk mendapatkan hasil tersebut, rumus affine dihitung terhadap basisnya yang diinduksi dari struktur simplektiknya. Lebih jauh, metode penelitian yang digunakan adalah studi literatur terhadap beberapa artikel yang relevan. Sebagai hasil utamanya, diperoleh rumus eksplisit struktur affine pada aljabar Lie dari grup Lie similitude berdimensi 4.

Kata kunci: Aljabar lie, grup lie similitude, struktur affine

Dikirim: 28 Juni 2020; Diterima: 25 Agustus 2020; Dipublikasikan: 30 September 2020

Cara sitasi: Kurniadi, E., Gusriani, N \& Subartini, B. (2020). Struktur affine aljabar lie real dari grup lie similitude berdimensi 4. Teorema: Teori dan Riset Matematika, 5(2), 163-168. 


\section{PENDAHULUAN}

Dalam penelitian sebelumnya, pengklasifikasian kelas isomorfisma aljabar Lie Frobenius telah diperoleh untuk yang berdimensi $\leq 6$ (Csikós \& Verhóczki, 2007). Salah satu kelas isomorfisma tersebut adalah aljabar Lie Frobenius berdimensi $4 \mathrm{~g}(\delta)$ dengan $\delta \neq 0 \in F$ atas suatu lapangan $F$ dengan karakteristik sama dengan nol. Misalkan basis $S:=\left\{\zeta_{k}\right\}_{k=1}^{4}$ basis untuk $\mathfrak{g}(\delta)$ dengan bracket tak nolnya diberikan sebagai berikut:

$$
\begin{aligned}
{\left[\zeta_{3}, \zeta_{1}\right]=\zeta_{1}, } & {\left[\zeta_{3}, \zeta_{2}\right]=\zeta_{2} } \\
{\left[\zeta_{4}, \zeta_{2}\right]=\zeta_{1}, } & {\left[\zeta_{4}, \zeta_{1}\right]=-\delta \zeta_{2}, \quad 0 \neq \delta \in F . }
\end{aligned}
$$

Untuk kasus lapangan $F$ adalah lapangan real $\mathbb{R}$ dan untuk $\delta=1$, maka aljabar Lie Frobenius berdimensi 4 dengan bracket tak nolnya diberikan oleh persamaan (1) adalah aljabar Lie real dari grup Lie similitude berdimensi 4 (Kurniadi, 2019a). Dengan kata lain $g(1):=\operatorname{Lie}\left(\mathbb{R}^{2} \rtimes(\mathbb{R} \oplus\right.$ SO(2)) dengan Lie $\left(\mathbb{R}^{2} \rtimes(\mathbb{R} \oplus \mathrm{SO}(2))\right.$ adalah notasi untuk aljabar Lie dari grup Lie similitude $\operatorname{Sim}(2):=\mathbb{R}^{2} \rtimes(\mathbb{R} \oplus S O(2))$ berdimensi 4 dan $S O(2)$ adalah grup Lie dari matriks ortogonal dengan determinannya sama dengan 1 .

Di sisi lain, gagasan tentang struktur affine pada suatu aljabar Lie telah muncul dalam berbagai area yang berbeda baik dalam konteks matematika atau fisika (Burde, 2015). Misalkan $\zeta_{1}{ }^{\prime}, \zeta_{2}{ }^{\prime}$, dan $\zeta_{3}{ }^{\prime}$ elemen-elemen suatu aljabar Lie. Asosiator dari ketiga elemen tersebut didefinisikan oleh:

$$
\mathcal{E}\left(\zeta_{1}{ }^{\prime}, \zeta_{2}{ }^{\prime}, \zeta_{3}{ }^{\prime}\right):=\left(\zeta_{1}{ }^{\prime} \zeta_{2}{ }^{\prime}\right) \zeta_{3}{ }^{\prime}-\zeta_{1}{ }^{\prime}\left(\zeta_{2}{ }^{\prime} \zeta_{3}{ }^{\prime}\right)
$$

Struktur affine pada suatu Lie algebra terjadi jika dipenuhi:

$$
\begin{aligned}
& \mathcal{E}\left(\zeta_{1}{ }^{\prime}, \zeta_{2}{ }^{\prime}, \zeta_{3}{ }^{\prime}\right)=\mathcal{E}\left(\zeta_{2}{ }^{\prime}, \zeta_{1}{ }^{\prime}, \zeta_{3}{ }^{\prime}\right) . \\
& {\left[\zeta_{1}{ }^{\prime}, \zeta_{2}{ }^{\prime}\right]=\zeta_{1}{ }^{\prime} \zeta_{2}{ }^{\prime}-\zeta_{2}{ }^{\prime} \zeta_{1}{ }^{\prime} .}
\end{aligned}
$$

Tentu saja tidak semua aljabar Lie atau grup Lie mempunyai struktur affine. Sebagai contoh grup Lie nilpoten filiform berdimensi $n$ dengan $10 \leq n \leq 13$ tidak mempunyai struktur affine (Burde, 2015). Di sisi lain, aljabar Lie Heisenberg berdimensi 3 mempunyai struktur affine yang diperoleh melalui konstruksi pemetaan affinenya (Kurniadi, 2019b).

Dalam penelitian ini diperoleh conjecture bahwa aljabar Lie real $g(1)$ dari grup Lie similitude berdimensi 4 yang bracket tak nolnya diberikan oleh persamaan (6) senantiasa mempunyai struktur affine. Adapun bentuk eksplisit dari struktur affine pada aljabar Lie $\mathfrak{g}(1)$ disajikan pada Tabel 1.

Tabel 1. Struktur affine pada $g$

\begin{tabular}{llll}
\hline Untuk $\boldsymbol{k}=\mathbf{1}$ & Untuk $\boldsymbol{k}=\mathbf{2}$ & Untuk $\boldsymbol{k}=\mathbf{3}$ & Untuk $\boldsymbol{k}=\mathbf{1}$ \\
\hline$\zeta_{1}^{2}=0$ & $\zeta_{2} \zeta_{1}=0$ & $\zeta_{3} \zeta_{1}=0$ & $\zeta_{4} \zeta_{1}=0$ \\
$\zeta_{1} \zeta_{2}=0$ & $\zeta_{2}^{2}=0$ & $\zeta_{3} \zeta_{2}=0$ & $\zeta_{4} \zeta_{2}=0$ \\
$\zeta_{1} \zeta_{3}=-\zeta_{1}$ & $\zeta_{2} \zeta_{3}=-\zeta_{2}$ & $\zeta_{3}^{2}=-\zeta_{3}$ & $\zeta_{4} \zeta_{3}=-\zeta_{4}$ \\
$\zeta_{1} \zeta_{4}=\zeta_{2}$ & $\zeta_{2} \zeta_{4}=-\zeta_{1}$ & $\zeta_{3} \zeta_{4}=-\zeta_{4}$ & $\zeta_{2}^{2}=-\zeta_{3}$ \\
\hline
\end{tabular}

Berbeda dengan hasil sebelumnya, dalam artikel ini dibahas tentang struktur affine pada aljabar Lie dari grup Lie similitude berdimensi 4 yang bersifat tidak nilpoten dan non unimodular. Hal ini tentu saja berbeda dengan sifat aljabar Lie Heisenberg atau filiform yang bersifat nilpoten dan unimodular. Tujuan penelitian yang diingin dicapai adalah sebagai berikut:

1. Membuktikan conjecture bahwa aljabar Lie dari grup Lie similitude berdimensi 4 senantiasa mempunyai struktur affine. 
2. Menentukan rumus ekplisit struktur affine pada pada aljabar Lie $\mathfrak{g}(1)$ sebagaimana disajikan dalam Tabel 1.

Selanjutnya perlu dibahas terlebih dahulu notasi-notasi dasar yang diperlukan dalam penelitian ini melalui kajian pustaka tentang aljabar Lie real berdimensi 4 dan struktur affine yang dapat dijelaskan sebagai berikut:

Teorema 1 (Hilgert \& Neeb, 2012). Ruang vektor real g dikatakan aljabar Lie jika bentuk bilinear $\mathfrak{g} \times \mathfrak{g} \ni(a, b) \mapsto[a, b] \in \mathfrak{g}$ bersifat anti-komutatif dan memenuhi identitas Jacoby, yaitu untuk setiap $a, b, c \in \mathfrak{g}$ berlaku:

1. $[a, b]=-[b, a]$,

2. $[a,[b, c]]=[[c, a], b]+[[a, b], c]$.

Misalkan $\mathrm{g}$ ajabar Lie real dan $\mathrm{g}^{*}$ menotasikan dual dari ruang vektor $\mathrm{g}$ yang didefinisikan sebagai berikut:

$$
\mathrm{g}^{*}:=\{f ; f: \mathfrak{g} \rightarrow \mathbb{R} \text { fungsional linear }\}
$$

dengan fungsional linearnya pada $x \in \mathfrak{g}$ diberikan oleh $\langle f, x\rangle:=f(x)$. Pada penelitian ini, salah satu kelas aljabar Lie yang dibahas adalah aljabar Lie real Frobenius berdimensi 4 yang isomorfik dengan aljabar Lie dari grup Lie similitude berdimensi 4. Secara formal, perhatikan definisi berikut ini:

Definisi 2 (Ooms, 1980). Aljabar Lie g dikatakan Frobenius jika terdapat fungsional linear $f$ di dual ruang vektor $\mathrm{g}^{*}$ sedemikian sehingga stabilizer

$$
\mathfrak{g}_{f}=\{\zeta \in \mathfrak{g} \quad ; \quad\langle f,[\zeta, \xi]\rangle=0, \forall \xi \in \mathfrak{g}\}=\{0\} .
$$

Titik $f$ yang memenuhi persamaan (5) dinamakan dengan fungsional Frobenius (Gerstenhaber \& Giaquinto, 2009). Contoh aljabar Lie Frobenius tersebut dapat dilihat dalam teorema di bawah ini yang sekaligus objek dalam penelitian ini.

Teorema 3 (Csikós \& Verhóczki, 2007). Aljabar Lie real Frobenius $\mathfrak{g}(\delta)$ dengan $\delta=1$ dan basis $S=\left\{\zeta_{1}, \zeta_{2}, \zeta_{3}, \zeta_{4}\right\}$ mempunyai bracket tak nol sebagai berikut:

$$
\begin{array}{ll}
{\left[\zeta_{3}, \zeta_{1}\right]=\zeta_{1},} & {\left[\zeta_{3}, \zeta_{2}\right]=\zeta_{2}} \\
{\left[\zeta_{4}, \zeta_{2}\right]=\zeta_{1},} & {\left[\zeta_{4}, \zeta_{1}\right]=-\zeta_{2} .}
\end{array}
$$

Misalkan $\mathrm{g}$ aljabar Lie dengan basis $\left\{\zeta_{k}\right\}_{k=1}^{2 m}$. Notasikan mat $\left(\left[\zeta_{k}, \zeta_{j}\right]\right), 1 \leq k, j \leq 2 m$ matriks yang entri-entrinya merupakan bracket dari $\mathrm{g}$ dan $\operatorname{mat}\left(\left\langle f,\left[\zeta_{k}, \zeta_{j}\right]\right\rangle\right)$ adalah matriks yang entrientrinya ditentukan oleh fungsional linear $f$ pada $\left[\zeta_{k}, \zeta_{j}\right]$.

Teorema 4 (Ooms, 1980). Misalkan g aljabar Lie dengan basis $\left\{\zeta_{k}\right\}_{k=1}^{2 m}$. Jika terdapat fungsional linear $f$ sedemikian sehingga determinan matriks mat $\left(\left\langle f,\left[\zeta_{k}, \zeta_{j}\right]\right\rangle\right)$ tidak sama dengan nol maka $\mathrm{g}$ adalah aljabar Lie Frobenius.

Dalam Subbab Hasil dan Pembahasan akan dibuktikan bahwa aljabar Lie $\mathfrak{g}(1)$ dalam Teorema 3 di atas adalah aljabar Lie Frobenius. Selanjutnya diperkenalkan notasi struktur affine pada suatu aljabar Lie sebagai berikut:

Teorema 5 (Burde, 2015). Misalkan g suatu aljabar Lie. Stuktur affine pada g adalah produk bilinear real

$$
\mathfrak{g} \times \mathfrak{g} \ni(a, b) \mapsto a b \in \mathfrak{g} .
$$

yang memenuhi persamaan (3). 
Khususnya untuk aljabar Lie Frobenius, eksistensi dari fungsional Frobenius $f \in \mathfrak{g}^{*}$ dapat digunakan untuk mencari produk bilinear real yang memenuhi persamaan (3). Di sisi lain, pada aljabar Lie Frobenius determinan matriks mat $\left(\left\langle f,\left[\zeta_{k}, \zeta_{j}\right]\right\rangle\right)$ sama dengan determinan bentuk bilinear ganti tanda

$$
B_{f}: \mathfrak{g} \times \mathfrak{g} \ni\left(\zeta_{k}, \zeta_{j}\right) \mapsto\left\langle f,\left[\zeta_{k}, \zeta_{j}\right]\right\rangle \in \mathbb{R}
$$

terhadap basis $\left\{\zeta_{k}\right\}_{k=1}^{2 m}$.

Selanjutnya, telah dibuktikan bahwa sembarang struktur simplektik linear form $\psi$ pada suatu Lie algebra $g$ dapat menginduksi persamaan (3) (Diatta et.al., 2020). Dengan kata lain, untuk setiap $\zeta_{1}{ }^{\prime}, \zeta_{2}{ }^{\prime}, \zeta_{3}{ }^{\prime} \in \mathrm{g}$ didapat:

$$
\psi\left(\zeta_{1}{ }^{\prime} \zeta_{2}{ }^{\prime}, \zeta_{3}{ }^{\prime}\right):=-\psi\left(\zeta_{2}{ }^{\prime},\left[\zeta_{1}{ }^{\prime}, \zeta_{3}{ }^{\prime}\right]\right)
$$

dengan $\psi$ didefinisikan mengikuti persamaan (8).

\section{METODE PENELITIAN}

Metode yang digunakan dalam penelitian ini adalah kajian pustaka khususnya tentang klasifikasi aljabar Lie Frobenius berdimensi 4 atas lapangan dengan karakteristik nol (Csikós \& Verhóczki, 2007), kemudian tentang aljabar simetrik kiri (Diatta \& Manga, 2014), dan terakhir tentang struktur affine pada aljabar Lie (Diatta et al., 2020). Langkah pertama, diberikan aljabar Lie real dari grup Lie similitude berdimensi 4 kemudian dibuktikan eksistensi struktur affine pada aljabar Lie tersebut dan secara eksplisit diberikan rumus struktur affine-nya.

\section{HASIL DAN PEMBAHASAN}

Pertama-tama aljabar Lie Frobenius $\mathrm{g}(\delta)$ dengan $\delta=1$ dalam Teorema 3 dinotasikan oleh $\mathfrak{g}(1)$. Aljabar Lie dari grup Lie similitude $\operatorname{Sim}(2)$ isomorfik dengan aljabar Lie Frobenius real $\mathfrak{g}(1)$ yang bracket-nya diberikan oleh persamaan (6). Dengan kata lain, $\mathfrak{g}(1):=\mathbb{R}^{2} \rtimes(\mathbb{R} \oplus$ $\mathfrak{s D}(2)$ ) dengan $\mathfrak{s}(2)$ adalah aljabar Lie dari $\mathrm{SO}(2)$.

Teorema 6 (Csikós dan Verhóczki, 2007). Aljabar Lie g(1) adalah aljabar Lie Frobenius dengan fungsional Frobeniusnya adalah $\zeta_{1}^{*}$.

Bukti. Pilih fungsional Frobenius $f:=\zeta_{1}^{*} \in \mathfrak{g}(1)^{*}$. Proses detail pemilihan fungsional Frobenius $f$ telah dikaji dalam penelitian sebelumnya (Kurniadi \& Ishi, 2019). Selanjutnya perhatikan bahwa

$$
\operatorname{det}\left(\operatorname{mat}\left(\left\langle\zeta_{1}^{*},\left[\zeta_{k}, \zeta_{j}\right]\right\rangle\right)\right)=\left|\begin{array}{cccc}
0 & 0 & -1 & 0 \\
0 & 0 & 0 & -1 \\
1 & 0 & 0 & 0 \\
0 & 1 & 0 & 0
\end{array}\right|=1 \neq 0 .
$$

Oleh karena itu, $g(1)$ adalah aljabar Lie Frobenius.

Selanjutnya diperoleh hasil utama dalam artikel ini sebagai berikut:

Proposisi 7. Aljabar Lie real $\mathrm{g}(1)$ dengan basis $S=\left\{\zeta_{1}, \zeta_{2}, \zeta_{3}, \zeta_{4}\right\}$ dan bracket tak nolnya diberikan oleh persamaan (6) mempunyai struktur affine.

Bukti. Pertama-tama dikonstruksi bentuk bilinear ganti tanda dari $\mathfrak{g}(1)$ sebagai berikut:

$$
B_{f}: \mathfrak{g}(1) \times \mathfrak{g}(1) \ni\left(\zeta_{k}, \zeta_{j}\right) \mapsto\left\langle f,\left[\zeta_{k}, \zeta_{j}\right]\right\rangle \in \mathbb{R}, \quad 1 \leq k, j \leq 4 .
$$

terhadap basis $\left\{\zeta_{k}\right\}_{k=1}^{4}$. Karena $\mathrm{g}(1)$ adalah aljabar Lie Frobenius maka terdapat fungsional Frobenius $f:=\zeta_{1}^{*} \in \mathfrak{g}(1)^{*}$ sedemikian sehingga $B_{f}$ adalah bentuk simplektik. Selanjutnya untuk $a, b \in \mathfrak{g}(1), \mathfrak{g}(1) \times \mathfrak{g}(1) \ni(a, b) \mapsto a b \in \mathfrak{g}(1)$ adalah produk bilinear di $\mathfrak{g}(1)$. Untuk elemenelemen $\zeta^{\prime}$ dan $\zeta^{\prime \prime}$ di $\mathrm{g}(1)$ maka terdapat skalar $\alpha_{i}, \beta_{j}$, dan $\gamma_{k}$ dengan $1 \leq i, j, k \leq 4$ sedemikian sehingga, 


$$
\zeta^{\prime}:=\sum_{i=1}^{4} \alpha_{i} \zeta_{i}, \quad \zeta^{\prime \prime}:=\sum_{j=1}^{4} \beta_{j} \zeta_{j}, \quad \zeta^{\prime} \zeta^{\prime \prime}:=\sum_{k=1}^{4} \gamma_{k} \zeta_{k}
$$

Dengan menggunakan persamaan (9) dan persamaan (11), diperoleh bahwa:

$$
B_{\zeta_{1}^{*}}\left(\zeta^{\prime} \zeta^{\prime \prime}, \zeta_{i}\right)=-\zeta_{1}^{*}\left(\zeta^{\prime \prime},\left[\zeta^{\prime}, \zeta_{i}\right]\right), \quad 1 \leq i \leq 4 \text {. }
$$

di mana $\zeta_{1}^{*}\left(\zeta_{i}\right)=1$ untuk $i=1$ dan nol untuk yang lainnya. Lebih jauh, karena persamaan (13) non-degenerate maka diperoleh penyelesaian untuk $\gamma_{i}$ dengan $1 \leq i \leq 4$ yang dinyatakan dalam perkalian $\alpha_{i}$ dan $\beta_{j}$ dengan $1 \leq i, j \leq 4$. Menulis ulang persamaan (12) dalam bentuk produk bilinear diperoleh:

$$
\zeta^{\prime} \zeta^{\prime \prime}=\left(\sum_{i=1}^{4} \alpha_{i} \zeta_{i}\right)\left(\sum_{j=1}^{4} \beta_{j} \zeta_{j}\right)=\sum_{k=1}^{4} \gamma_{k} \zeta_{k}
$$

Untuk mengkonstruksi produk $\zeta_{i} \zeta_{j}$ di $\mathrm{g}(1)$ dengan $1 \leq i, j \leq 4$, ditetapkan nilai-nilai $\alpha_{i}$ dan $\beta_{j}$ yang bersesuaian sedemikian persamaan (14) memenuhi persamaan (3). Dengan kata lain, $\mathfrak{g}(1)$ mempunyai struktur affine.

Akibat 8. Struktur affine pada aljabar Lie $\mathrm{g}(1)$ dengan basis $S=\left\{\zeta_{1}, \zeta_{2}, \zeta_{3}, \zeta_{4}\right\}$ dan bracket tak nolnya diberikan oleh persamaan (6) dapat dituliskan secara eksplisit sebagai berikut:

$$
\begin{array}{llll}
\zeta_{1}^{2}=0 & \zeta_{2} \zeta_{1}=0 & \zeta_{3} \zeta_{1}=0 & \zeta_{4} \zeta_{1}=0 \\
\zeta_{1} \zeta_{2}=0 & \zeta_{2}^{2}=0 & \zeta_{3} \zeta_{2}=0 & \zeta_{4} \zeta_{2}=0 \\
\zeta_{1} \zeta_{3}=-\zeta_{1} & \zeta_{2} \zeta_{3}=-\zeta_{2} & \zeta_{3}^{2}=-\zeta_{3} & \zeta_{4} \zeta_{3}=-\zeta_{4} \\
\zeta_{1} \zeta_{4}=\zeta_{2} & \zeta_{2} \zeta_{4}=-\zeta_{1} & \zeta_{3} \zeta_{4}=-\zeta_{4} & \zeta_{2}^{2}=-\zeta_{3}
\end{array}
$$

Bukti. Menggunakan persamaan (11)—(14) dan bracket $g(1)$ pada persamaan (6) diperoleh penyelesaian untuk $\gamma_{i}$ dengan $1 \leq i \leq 4$ yang dapat dinyatakan dalam perkalian antara skalar $\alpha_{i}$ dan $\beta_{j}$ dengan $1 \leq i, j \leq 4$. Dalam hal ini:

1. $\gamma_{1}=-\left(\beta_{3} \alpha_{1}+\beta_{4} \alpha_{2}\right)$,

2. $\gamma_{2}=-\left(\beta_{3} \alpha_{2}-\beta_{4} \alpha_{1}\right)$,

3. $\gamma_{3}=-\left(\beta_{3} \alpha_{3}-\beta_{4} \alpha_{4}\right)$,

4. $\gamma_{4}=-\left(\beta_{4} \alpha_{3}+\beta_{3} \alpha_{4}\right)$.

Sehingga persamaan (14) menjadi:

$$
\begin{aligned}
\zeta^{\prime} \zeta^{\prime \prime}=\left(\sum_{i=1}^{4} \alpha_{i} \zeta_{i}\right)\left(\sum_{j=1}^{4} \beta_{j} \zeta_{j}\right) & =\sum_{k=1}^{4} \gamma_{k} \zeta_{k}=-\left(\beta_{3} \alpha_{1}+\beta_{4} \alpha_{2}\right) \zeta_{1}-\left(\beta_{3} \alpha_{2}-\beta_{4} \alpha_{1}\right) \zeta_{2} \\
-\left(\beta_{3} \alpha_{3}-\beta_{4} \alpha_{4}\right) \zeta_{3}-\left(\beta_{4} \alpha_{3}+\beta_{3} \alpha_{4}\right) \zeta_{4} . &
\end{aligned}
$$

Dengan menetapkan nilai-nilai $\alpha_{i}$ dan $\beta_{j}$ yang bersesuaian maka diperoleh rumus eksplisit affine seperti dalam tabel di atas.

\section{KESIMPULAN}

Dari hasil dan pembahasan, telah dibuktikan dalam Proposisi 7 bahwa aljabar Lie real dari grup Lie similitude berdimensi 4 mempunyai struktur affine. Selanjutnya dalam Akibat 8 telah diperoleh pula rumus eksplisit untuk struktur affine aljabar Lie real dari grup Lie similitude berdimensi 4 seperti dalam Tabel 1.

\section{REKOMENDASI}

Masalah yang masing terbuka di sini adalah bagaimana dengan struktur affine aljabar Lie Frobenius berdimensi 4 lainnya dan bagaimana pula bentuk eksplisit rumus affinenya. 


\section{UCAPAN TERIMAKASIH}

Penulis mengucapkan terimakasih kepada Universitas Padjadjaran yang telah mendanai penelitian ini melalui Riset Percepatan Lektor Kepala (RPLK) tahun 2020 dengan nomor kontrak 1427/UN6.3.1/LT/2020.

\section{DAFTAR PUSTAKA}

Burde, D. (2015). Left-symmetric algebras, or pre-lie algebras in geometry and physics. ArXiv:MathPh/0509016v2.

Csikós, B., \& Verhóczki, L. (2007). Classification of frobenius lie algebras of dimension $\leq 6$. Publicationes Mathematicae, 70(3-4), 427-51.

Diatta, A., \& Manga, B. (2014). On properties of principal elements of frobenius lie algebras. J. Lie Theory, 24(3), 849-64.

Diatta, A., Manga, B., \& Mbaye, A. (2020). On systems of commuting matrices, frobenius lie algebras and gerstenhaber's theorem. ArXiv:2002.08737.

Gerstenhaber, M., \& Giaquinto, A. (2009). The principal element of a frobenius lie algebra. Letters in Mathematical Physics, 88(1-3), 333-41.

Hilgert, J., \& Neeb, K-H. (2012). Structure and geometry of lie groups. Monographs in Mathematics, New York: Springer.

Kurniadi, E. (2019a). Harmonic analysis for finite dimensional real frobenius lie algebras. Disertasi Doktor. Respository Nagoya University, Nagoya, Jepang.

Kurniadi, E. (2019b). Struktur affine pada aljabar lie heisenberg berdimensi 3. Prosiding Seminar Nasional Statistika, November 2019, Departemen Statistika FMIPA Unpad, 8(1).

Kurniadi, E., \& Ishi, H. (2019). Harmonic analysis for 4-dimensional real frobenius lie algebras. Springer Proceeding in Mathematics \& Statistics. Springer Proceeding in Mathematics \& Statistics.

Ooms, A. I. (1980). On frobenius lie algebras. Journal of Algebra, 8(1), 13-52. 